\title{
Gestational and Hormonal Effects on Magnesium Sulfate's Ability to Inhibit Mouse Uterine Contractility
}

Reproductive Sciences I570-1579

(C) The Author(s) 2019

DOI: 10.1007/s43032-020-00185-8

\author{
Blessing E. Osaghae, MRes, PhD', Sarah Arrowsmith, PhD', \\ and Susan Wray, PhD'
}

\begin{abstract}
Magnesium sulfate is used as a tocolytic, but clinical efficacy has been seriously questioned. Our objective was to use controlled ex vivo conditions and known pregnancy stages, to investigate how 2 key factors, hormones and gestation, affect magnesium's tocolytic ability. We hypothesized that these factors could underlie the varying clinical findings around magnesium's efficacy. Myometrial strips were obtained from nonpregnant $(n=10)$, mid-pregnant $(n=12)$, and term-pregnant $(n=I I)$ mouse uterus. The strips were mounted in organ baths superfused with oxygenated physiological saline at $\mathrm{pH} 7.4$ and $37^{\circ} \mathrm{C}$. The effect of different concentrations of $\mathrm{MgSO}_{4}(2-20 \mathrm{mM})$ was examined on spontaneous and oxytocin-induced (0.5-I nM) contractions. Contractile properties (amplitude, frequency, and area under the curve) were measured before and after application of magnesium. Magnesium sulfate had a dose-dependent inhibitory effect on both spontaneous and oxytocin-induced contractions but was less effective in the presence of oxytocin. In spontaneous contractions, magnesium was more potent as gestation progressed $(P<.000 \mathrm{I})$. In the presence of oxytocin, however, there were no significant gestational differences in its effects on contraction. The rapid onset and reversal of magnesium's effects suggest an extracellular action on calcium entry. Taken together, we conclude that magnesium's actions are influenced by both gestational state and hormones, such that, at least in mice, it is least effective in early gestation with oxytocin present and most effective at term in the absence of oxytocin. That magnesium is least effective preterm and oxytocin decreases its effectiveness throughout gestation, may explain its disappointing clinical effects as a tocolytic.
\end{abstract}

\section{Keywords}

tocolysis, contraction, uterus, preterm birth, oxytocin

\section{Introduction}

The high incidence of preterm birth, $>10 \%$ of births worldwide, remains unchanged despite much research effort and advancement in understanding uterine physiology. ${ }^{1}$ It is the single largest cause of mortality and morbidity in newborns. Several tocolytics including oxytocin-receptor antagonists, for example, atosiban; prostaglandin synthesis inhibitors, for example, indomethacin; calcium channel blockers, for example, nifedipine; $\beta$-2 agonists, for example, ritodrine; and magnesium sulfate $\left(\mathrm{MgSO}_{4}\right)$ have been developed to help prolong pregnancy, by reducing or slowing uterine contractions when preterm labor threatens. Unfortunately, it remains the case that none are ideal in terms of either efficacy or side effects, and perhaps not surprisingly there is little international consensus on which tocolytic to use to help manage spontaneous preterm labor.

Magnesium sulfate was described as a tocolytic in $1959^{2}$ and shortly after became the preferred drug in treating preterm labor. More recently, however, studies including Cochrane systemic reviews ${ }^{3,4}$ have suggested that $\mathrm{MgSO}_{4}$ is ineffective in the treatment of preterm labor. For example, Crowther et al concluded that it was no better than placebo for the primary outcome of giving birth within 48 hours of trial entry, and nor was there any significant difference for the primary outcome of serious infant morbidity. ${ }^{3}$ In contrast, $\mathrm{MgSO}_{4}$ has been shown to be the drug of choice in treatment of seizures in eclampsia ${ }^{5}$ and prevention of preeclampsia in hypertensive pregnant women. ${ }^{6}$ Additionally, $\mathrm{MgSO}_{4}$ has been shown to have neuroprotective effects in preterm fetuses at delivery, reducing the risk of death, cerebral palsy, and gross motor dysfunction. ${ }^{7}$

\footnotetext{
' Department of Cellular and Molecular Physiology, University Department, Harris-Wellbeing Preterm Birth Research Centre, The Institute of Translational Medicine, University of Liverpool, Liverpool, UK
}

\section{Corresponding Author:}

Susan Wray, Department of Molecular and Cellular Physiology, University Department, Harris-Wellbeing Preterm Birth Research Centre, Institute of Translational Medicine, University of Liverpool, First floor Liverpool Women's Hospital, Crown Street, Liverpool L8 7SS, UK.

Email: s.wray@liv.ac.uk 
In contrast to clinical findings, in vitro studies have consistently found that magnesium has a relaxant effect on smooth muscles, including airway ${ }^{8}$ and vascular. ${ }^{9}$ Studies in myometrial smooth muscle show it to be a relaxant in several spe$\operatorname{cies}^{10-13}$; it significantly inhibits contractions in a concentration-dependent manner. ${ }^{12,14}$

In smooth muscles, magnesium inhibits contractility via multiple mechanisms including effects on extracellular calcium entry, intracellular calcium release, and calcium oscillations. ${ }^{15}$ It primarily acts by competing with $\mathrm{Ca}^{2+}$ at the L-type, voltage-operated calcium channel (VOCC), resulting in a decrease in intracellular calcium concentration. ${ }^{15}$ The channel is comprised of 4 subunits, of which $\alpha-1$ is the pore forming, voltage sensitive and conducting component, and the others modulate its activity. Progression of gestation has been linked to an increase in $\alpha-1$ expression, and VOCC activity increases close to term. ${ }^{16-18}$ These findings suggest that calcium channel density and expression increases with gestation. As magnesium's main action is at the calcium channel, the question arises: Could these changes in calcium channel density and expression alter the effectiveness of magnesium at different gestational ages?

Of the hormonal changes around labor, oxytocin has a pivotal role. ${ }^{19}$ Oxytocin stimulates myometrial activity via a variety of mechanisms, including increasing $\mathrm{Ca}^{2+}$ entry into the myometrium via L-type channels and stimulating calcium release from the sarcoplasmic reticulum (SR). ${ }^{20,21}$ Oxytocin stimulation would, therefore, be expected to mitigate the actions of magnesium. Thus, if women with threatened preterm labor had differing levels of oxytocin or differences in levels of expression of its receptor, ${ }^{22}$ this may also alter responsiveness to magnesium tocolysis in vivo.

It would be of benefit if the in vivo and in vitro findings concerning magnesium's effects on uterine contractility could be reconciled. This could then enable a stratification of which threatened spontaneous preterm labors may benefit from its use as a tocolytic. Our approach was to consider if there may be physiological factors that affect magnesium's efficacy in vivo. Preterm births are defined as those before 37 completed weeks of gestation, and thus cover a very large gestational age range and much change in myometrial physiology and hormonal conditions. $^{23-26}$ These changes can be anticipated to also affect magnesium's tocolytic ability.

While the effect of magnesium in animal and human termpregnant myometrium on spontaneous ${ }^{12-14}$ and oxytocininduced contractions ${ }^{12,14,15}$ has received some attention, the effect of magnesium at different gestational stages has not been systematically investigated. In addition, neither has the influence of oxytocin on magnesium's action been studied throughout gestation. Furthermore, much can be learned from mouse animal models, but we can find only one study where they have been used to look at magnesium's relaxant effect and that was on day 14 of pregnancy in lipopolysaccharide (LPS)-treated animals. $^{27}$

The aim of this study, therefore, was to investigate whether the relaxant effects of magnesium are altered by gestational state and to test the hypothesis that the stimulation provided by oxytocin will significantly reduce the relaxant effects of magnesium.

\section{Methods}

\section{Solutions}

All study solutions were prepared fresh at the start of each experiment by direct dissolving of $\mathrm{MgSO}_{4}$ or $\mathrm{MgCl}_{2}$ in buffered physiological saline solution (PSS) composed of (mM): $\mathrm{NaCl} 154, \mathrm{KCl} 5.6, \mathrm{MgSO}_{4} 1.2, \mathrm{CaCl}_{2} 2$, glucose 8 , and HEPES 10.2. ${ }^{28}$ Basal or control $\mathrm{MgSO}_{4}$, therefore, was 1.2 $\mathrm{mM}$. Oxytocin was prepared in distilled water and added to the PSS to give a final concentration of $0.5 \mathrm{nM}$ (pregnant tissues) or $1 \mathrm{nM}$ (nonpregnant tissues). A $1 \mathrm{nM}$ concentration of oxytocin was used for nonpregnant tissues to ensure a similar stimulation to that seen in pregnant tissues was achieved. The concentration of water did not exceed $0.01 \%$. All chemicals were obtained from Sigma, UK.

\section{Tissue Collection and Preparation}

Nonpregnant, 14- and 16-day (referred to as mid-pregnant) and 18-day (term) pregnant mice were humanely killed using $\mathrm{CO}_{2}$ anesthesia and cervical dislocation, in accordance with UK Home Office regulations. ${ }^{19}$ All mice used were between 8 and 10 weeks old. The uterus was removed, cleaned of placentas and membranes (where applicable), and full-thickness (endometrium intact) myometrial strips $(1 \mathrm{~mm} \times 2 \mathrm{~mm} \times 10 \mathrm{~mm})$ were dissected along the longitudinal axis. ${ }^{21}$ Using surgical thread, individual strips were mounted between a fixed support and a $10 \mathrm{~g}$ isometric force transducer (World Precision Instruments, UK) within a $5 \mathrm{~mL}$ tissue bath (Linton Instruments, UK) under a resting tension of $5 \mathrm{mN}$ and were continuously superfused with oxygenated $\left(95 \% \mathrm{O}_{2}, 5 \% \mathrm{CO}_{2}\right) \mathrm{PSS}$ at $\mathrm{pH} 7.4$, at a rate of $5 \mathrm{~mL} / \mathrm{min}$ and maintained at $37^{\circ} \mathrm{C}$ to mimic physiological conditions. ${ }^{29}$

\section{Experimental Protocol}

For spontaneous contractions, strips were allowed to equilibrate for 45 to 60 minutes until regular, frequent, and equal amplitude contractions were observed. For oxytocin-induced contractions, strips achieved regular spontaneous activity as above, ahead of addition of oxytocin that remained in the superfusate throughout. The uterine strips were then exposed to increasing concentrations of $\mathrm{MgSO}_{4}$ from 2 to $10 \mathrm{mM}$ (spontaneous) and 2 to $12 \mathrm{mM}$ (oxytocin-induced) for 15 minutes or $\mathrm{MgSO}_{4}$ or $\mathrm{MgCl}_{2}(10$ and $20 \mathrm{mM})$, either in the presence or absence of oxytocin.

\section{Analysis and Statistics}

Myometrial contractions were continuously recorded via the force transducer connected to a data acquisition system equipped with Labtrax software (World Precision 
Table I. Changes in Contractile Properties of Spontaneous Contractions in Response $\mathrm{MgSO}_{4}{ }^{\mathrm{a}}$

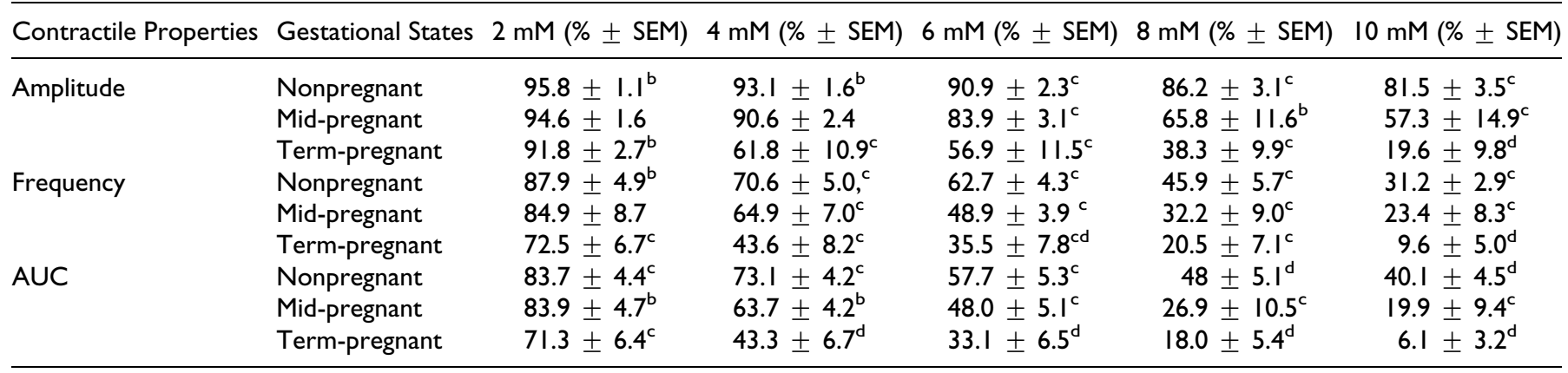

Abbreviation: AUC, area under the curve.

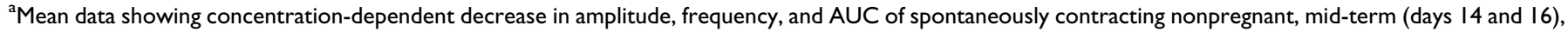

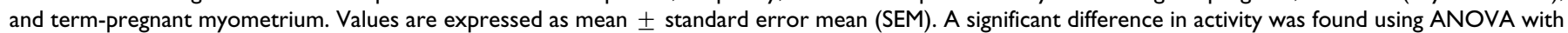
Bonferroni post hoc analysis.

bignificant difference compared to control period (100\%) at $P<.05$.

'Significant difference compared to control period (I00\%) at $P<.0$ I.

${ }^{\mathrm{d}}$ Significant difference compared to control period (I00\%) at $P<.000 \mathrm{I}$.

Table 2. Changes in Contractile Properties of Oxytocin-Induced Contractions in Response to $\mathrm{MgSO}_{4}{ }^{\mathrm{a}}$

\begin{tabular}{|c|c|c|c|c|c|c|c|c|}
\hline $\begin{array}{l}\text { Contractile } \\
\text { Properties }\end{array}$ & $\begin{array}{l}\text { Gestational } \\
\text { States }\end{array}$ & $\begin{array}{c}2 \mathrm{mM} \\
(\% \pm \mathrm{SEM})\end{array}$ & $\begin{array}{c}4 \mathrm{mM} \\
(\% \pm \mathrm{SEM})\end{array}$ & $\begin{array}{c}6 \mathrm{mM} \\
(\% \pm \mathrm{SEM})\end{array}$ & $\begin{array}{c}8 \mathrm{mM} \\
(\% \pm \mathrm{SEM})\end{array}$ & $\begin{array}{c}10 \mathrm{mM} \\
(\% \pm \mathrm{SEM})\end{array}$ & $\begin{array}{c}12 \mathrm{mM} \\
(\% \pm \mathrm{SEM})\end{array}$ & $\begin{array}{c}20 \mathrm{mM} \\
(\% \pm \mathrm{SEM})\end{array}$ \\
\hline \multirow[t]{2}{*}{ Amplitude } & Nonpregnant & $98.7 \pm 0.7$ & $96.7 \pm 1.1^{b}$ & $95.0 \pm 2.1^{b}$ & $92.7 \pm 2.4^{b}$ & $90.8 \pm 2.6^{c}$ & $89.3 \pm 1.9^{b}$ & $81.2 \pm 5.4^{b}$ \\
\hline & Term-pregnant & $98.8 \pm 1.0^{b}$ & $95.5 \pm 1.2^{c}$ & $90.6 \pm 1.7^{c}$ & $84.0 \pm 2.0^{c}$ & $71.3 \pm 7.4^{\mathrm{d}}$ & $71.0 \pm 4.9^{d}$ & $4.4 \pm 4.4^{c}$ \\
\hline \multirow[t]{2}{*}{ Frequency } & Nonpregnant & $85.3 \pm 2.7^{c}$ & $66.1 \pm 4.0^{c}$ & $48.0 \pm 5.0^{c}$ & $40.0 \pm 5.6^{c}$ & $35.7 \pm 5.5^{c}$ & $36.1 \pm 4.1^{d}$ & $47.0 \pm 7.9^{c}$ \\
\hline & Mid-pregnant & $92.8 \pm 3.1^{b}$ & $90.4 \pm 4.1^{\mathrm{b}}$ & $79.9 \pm 11.8^{c}$ & $75.4 \pm 11.9^{c}$ & $67.5 \pm 10.5^{c}$ & $58.0 \pm 13.2^{c}$ & $2.5 \pm 0.1$ \\
\hline \multirow{2}{*}{ AUC } & Mid-pregnant & $94.7 \pm 2.5^{\mathrm{b}}$ & $90.0 \pm 3.3^{b}$ & $67.1 \pm 11.0^{c}$ & $65.6 \pm 4.5^{d}$ & $48.8 \pm 9.3^{c}$ & $34.9 \pm 8.8^{c}$ & $2.1 \pm 0.9^{d}$ \\
\hline & Term-pregnant & $93.8 \pm 1.2$ & $83.3 \pm 1.5^{c}$ & $73.6 \pm 2.6^{c}$ & $60.9 \pm 3.5^{c}$ & $50.5 \pm 3.9^{c}$ & $41.3 \pm 6.7^{c}$ & $1.7 \pm 1.7^{\mathrm{d}}$ \\
\hline
\end{tabular}

Abbreviation: AUC, area under the curve.

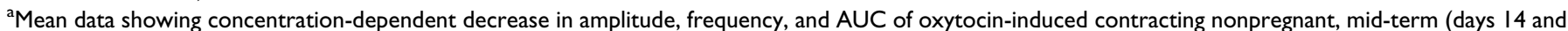

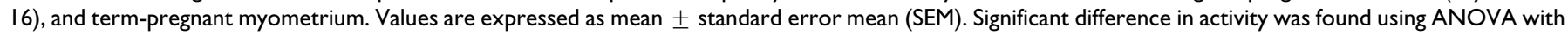
Bonferroni post hoc analysis.

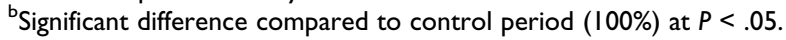

'Significant difference compared to control period (I00\%) at $P<.0 \mathrm{I}$.

${ }^{\mathrm{d}}$ Significant difference compared to control period (100\%) at $P<.000 \mathrm{I}$.

Instruments). ${ }^{29}$ For each recording, the amplitude, frequency, and force integral (area under the curve [AUC]) of contraction were measured, both during the control period (contractions occurring in the 10 minutes immediately preceding the first application of magnesium) and during the final 10 minutes of each step in the concentration-response period. Data were analyzed using Origin Pro 2015 (Origin Lab Corporation, Massachusetts) and are presented as percentage of control to reflect the effect of magnesium, where the control period is taken as $100 \%$. Values given are mean \pm standard error of the mean unless stated otherwise and were compared by analysis of variance (ANOVA), $\mathrm{n}$ is the number of myometrial tissue strips, each one from a different animal, $\mathrm{N}$.

Concentration-response curves for AUC were fitted to the logistic equation with the use of nonlinear regression. The concentration at which $\mathrm{MgSO}_{4}$ caused a $50 \%$ reduction $\left(\mathrm{IC}_{50}\right)$ in overall contractile activity (AUC) was calculated.
$\operatorname{LogIC}_{50}$ s were compared by the extra sum of squares $F$ test or ANOVA followed by Bonferroni post hoc analysis.

All statistical analysis was carried out using Graphpad Prism 5 , significance was taken as $P<.05$. Summary of analyses performed:

(1) Effect of $\mathrm{MgSO}_{4}$ versus $\mathrm{MgCl}_{2}$ - compared using $t$ tests.

(2) Tables 1 and 2-ANOVA with Bonferroni post hoc correction.

(3) Comparison of $\log \mathrm{IC}_{50}$ values for magnesium on spontaneous or oxytocin contractions between gestational groups-ANOVA with Bonferroni post hoc correction.

(4) Comparison of $\log \mathrm{IC}_{50}$ values for effect of magnesium on spontaneous versus oxytocin-simulated contractions at each gestation-extra sum of squares $F$ test. 


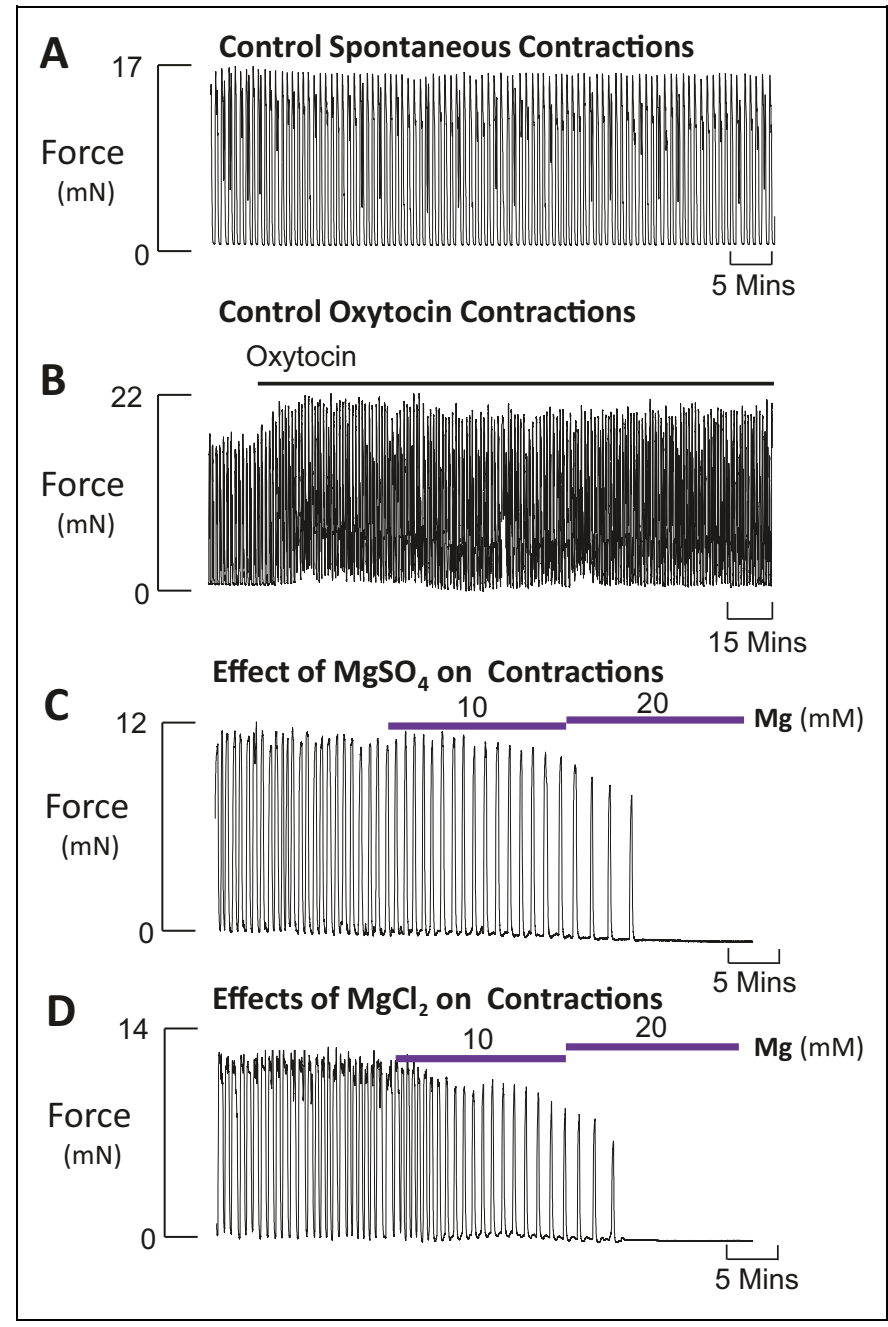

Figure I. The effects of magnesium on contractions of mouse myometrium. Typical records showing contractions obtained from termpregnant mouse myometrium. In this and all subsequent figures, data were obtained at $37^{\circ} \mathrm{C}$ and $\mathrm{pH} 7.4$, with tissues superfused with physiological saline (containing I. $2 \mathrm{mMMgSO}_{4}$ ), in the absence (A, B) and presence of increased (10 or $20 \mathrm{mM}$ ) magnesium as sulfate $(C)$ or chloride (D) salt. Traces B- were in the presence of oxytocin (0.5 nM).

\section{Results}

\section{Control Data and Effects of Magnesium on Late- Pregnant Mouse Myometrium}

As there were little or no data concerning the actions of magnesium on mouse myometrium, initial experiments were performed to determine that magnesium affected contractility and that the effects of $\mathrm{MgSO}_{4}$ were due to magnesium and not the anion, and to obtain an indicative concentration for concentration-response curves.

As shown in Figure 1A and B, stable, control contractions from pregnant mouse myometrium could be obtained for several hours without decrement in spontaneously active (A) and oxytocin-stimulated (B) tissues (typical of 9 preparations). Figure 1 also shows typical traces obtained using either $10 \mathrm{mM}$ and
$20 \mathrm{mM} \mathrm{MgSO}_{4}$ (1C) or $\mathrm{MgCl}_{2}$ (1D), from 3 paired experiments (different animals), on oxytocin-stimulated pregnant myometrium. No significant differences were found between the effect of $10 \mathrm{mM} \mathrm{MgSO} 4$ and $\mathrm{MgCl}_{2}$ : amplitude: $70 \% \pm 14 \%$ and $77 \% \pm 9 \%$; AUC: $50 \% \pm 7 \%$ and $58 \% \pm 2 \%$, respectively, nor were any significant differences found between $\mathrm{MgSO}_{4}$ or $\mathrm{MgCl}_{2}$ during spontaneous activity (data not shown). Based on these data, the remaining experiments were performed using $\mathrm{MgSO}_{4}$ as it is the sulfated form which is used clinically, and the effects of different concentrations and gestation were examined.

\section{Effects of Magnesium on Spontaneous Contractions at Different Gestational States}

The effects of the application of increasing concentrations of $\mathrm{MgSO}_{4}$ in the superfusate bathing the spontaneously contracting myometrial strips were examined and compared at days 14,16 , and 18 of pregnancy and nonpregnant. Concentration-dependent inhibitory effects of magnesium were found at each gestational state investigated as well as nonpregnant tissues. Representative isometric recordings are shown in Figure 2. For all preparations, there was a decrease in frequency of contractions followed by a reduction in contraction amplitude. The mean data for frequency, amplitude, and AUC for spontaneous contractions for each group are given in Table 1. The data show that magnesium reduces spontaneous activity of the myometrium in all tissue groups, with its effect becoming more marked (and significant) as term approaches: In nonpregnant and day 14 gestation tissues, contractions in the presence of $10 \mathrm{mM} \mathrm{MgSO}$ still persisted, with the AUC being $40 \%$ and $18 \%$ of control, respectively (Figure 2A-C). In term-pregnant myometrium, $10 \mathrm{mM} \mathrm{MgSO}_{4}$ further and significantly reduced the AUC to negligible values (6\%, Figure 2D). The increased effects of magnesium with gestation can also be appreciated from the fact that, in nonpregnant, days 14 and 16 tissues, contractions were abolished in just 1 of 22 preparations (on day $16)$, whereas at term, magnesium abolished contractions in over half the tissues (6/11 preparations). In all preparations, however, including those where contractions were abolished (eg, Figure 2D), spontaneous contractions recovered to control values upon return to normal physiological saline $\left(\mathrm{MgSO}_{4} 1.2 \mathrm{mM}\right)$.

Plotting AUC concentration-response curves and calculating the $\mathrm{IC}_{50}$ values for magnesium confirmed the mean data findings. The order of potency for $\mathrm{MgSO}_{4}$ on spontaneous contractions was term-pregnant $>$ mid-pregnant $>$ nonpregnant (Figure 2E). The $\mathrm{IC}_{50}$ values fell from $7.06 \pm 0.32 \mathrm{mM}$ (nonpregnant, $\mathrm{n}=10$ ) to $4.75 \pm 0.21 \mathrm{mM}$ (day $14, \mathrm{n}=9$ ) to $3.08 \pm$ $0.16 \mathrm{mM}$ (term, $\mathrm{n}=11, \mathrm{P}<0.001$ ). There was no significant difference between the $\mathrm{IC}_{50}$ values for $\mathrm{MgSO}_{4}$ at days 14 and 16 gestation $(4.75 \pm 0.21 \mathrm{mM}$ and $5.50 \pm 0.26 \mathrm{mM}$, respectively, $P>.05)$. 

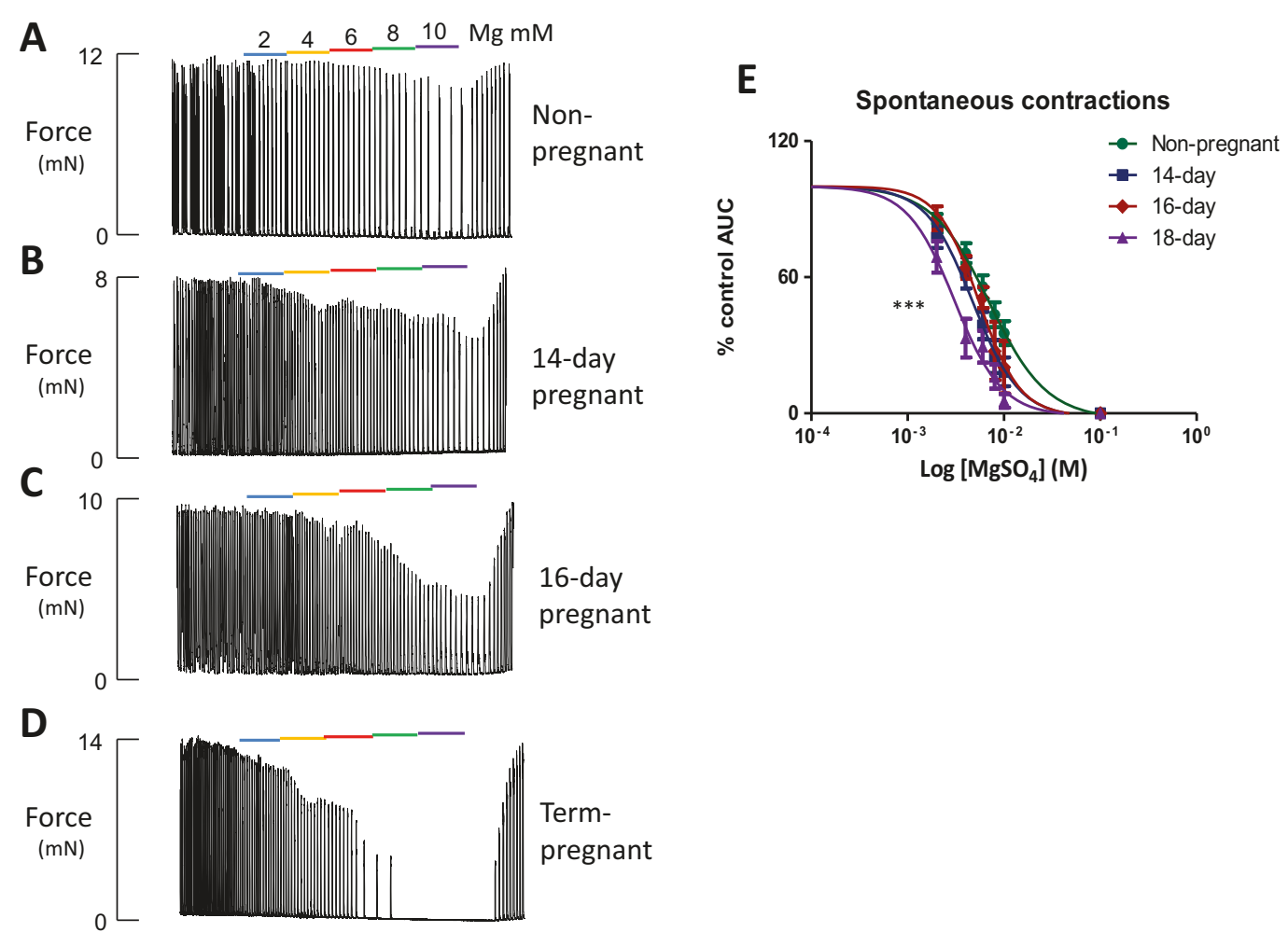

Figure 2. The effects of magnesium sulfate on spontaneous contractions of mouse myometrium. Representative isometric traces showing the effect of increasing concentrations of magnesium sulfate in (A) nonpregnant, (B) I4-day pregnant, (C), I6-day pregnant, and (D) term-pregnant myometrium. The colored bars indicate the 15-minute period when magnesium sulfate was added. In all gestational states, a reduction in amplitude and frequency was observed with increased concentration. E, The concentration-response curves showing the effect of magnesium sulfate on force area under the curve (AUC) at different gestational states (nonpregnant: green circle, I4-day: blue square, I6-day: red diamond, term pregnant: purple triangle). The concentration-response curves significantly shifted to the left as gestation increased $(P<.000 \mathrm{I})$. Significant difference was found using ANOVA with Bonferroni post hoc test. ANOVA indicates analysis of variance.

\section{Effects of Magnesium on Oxytocin-Induced Contractions at Different Gestational Stages}

Having found significant effects of magnesium on spontaneous contractility, we next investigated whether these effects were altered when the tissues were stimulated with oxytocin. Using the same protocol as for spontaneous contractions, the data obtained in the presence of oxytocin also showed a concentration-dependent decrease in all parameters of contraction. This was evident in all tissue groups. Representative traces showing the effect of $\mathrm{MgSO}_{4}$ in the presence of oxytocin are given in Figure 3A-D and the mean data are given in Table 2.

Unlike spontaneous activity, in the presence of oxytocin, the myometrium was still producing significant amounts of force at $10 \mathrm{mM}$ magnesium in all preparations. In order therefore to accurately plot concentration-response curves, assist with curve fitting, and better understand the response of the tissue, magnesium was increased to 12 and $20 \mathrm{mM}$. Typical responses to $20 \mathrm{mM}$ magnesium are shown in Figure 1C.

As is clear in the example traces in Figure 3, for all pregnant tissues, a less potent inhibition with magnesium was found in the presence of oxytocin compared to its application to spontaneous contractions, that is, without oxytocin (Figure 2). Additionally, in pregnant tissues, concentration-response curves for magnesium in the presence of oxytocin were also shifted to the right compared to spontaneous contractions (Figures 3E and 4B-D), resulting in significantly greater $\mathrm{IC}_{50}$ values with oxytocin stimulation. The greatest shift in $\mathrm{IC}_{50}$ values was seen for term-pregnant tissues from $3.08 \pm 0.16 \mathrm{mM}$ in spontaneous conditions to $9.75 \pm 0.21 \mathrm{mM}$ with oxytocin $(P<.0001)$. A significant shift in $\mathrm{IC}_{50}$ values was also seen for day 14 gestation tissues from $4.75 \pm 0.21 \mathrm{mM}$ in spontaneous conditions to $10.25 \pm 0.24 \mathrm{mM}$ in oxytocin $(P<.0001)$ and day 16 gestation tissues from $5.50 \pm 0.26 \mathrm{mM}$ in spontaneous conditions to 9.35 $\pm 0.38 \mathrm{mM}$ in oxytocin $(P=.0031)$. In contrast, in nonpregnant tissues, the presence of oxytocin (even at $1 \mathrm{nM}$ ) did not significantly alter the $\mathrm{IC}_{50}$ values for magnesium: $7.06 \pm 0.32 \mathrm{mM}$ in spontaneous to $8.07 \pm 0.40 \mathrm{mM}$ in the presence of oxytocin (Figure $4 \mathrm{~A}, P=.3236$ ); hence in nonpregnant tissues, magnesium is equipotent in the presence and absence of oxytocin.

Our data showed that a consequence of oxytocin significantly increasing the $\mathrm{IC}_{50}$ values in all pregnant tissues was that there were no longer any gestational differences between them, in the effects of magnesium (Figure 4). In other words, there was no significant difference in the inhibitory effect of 


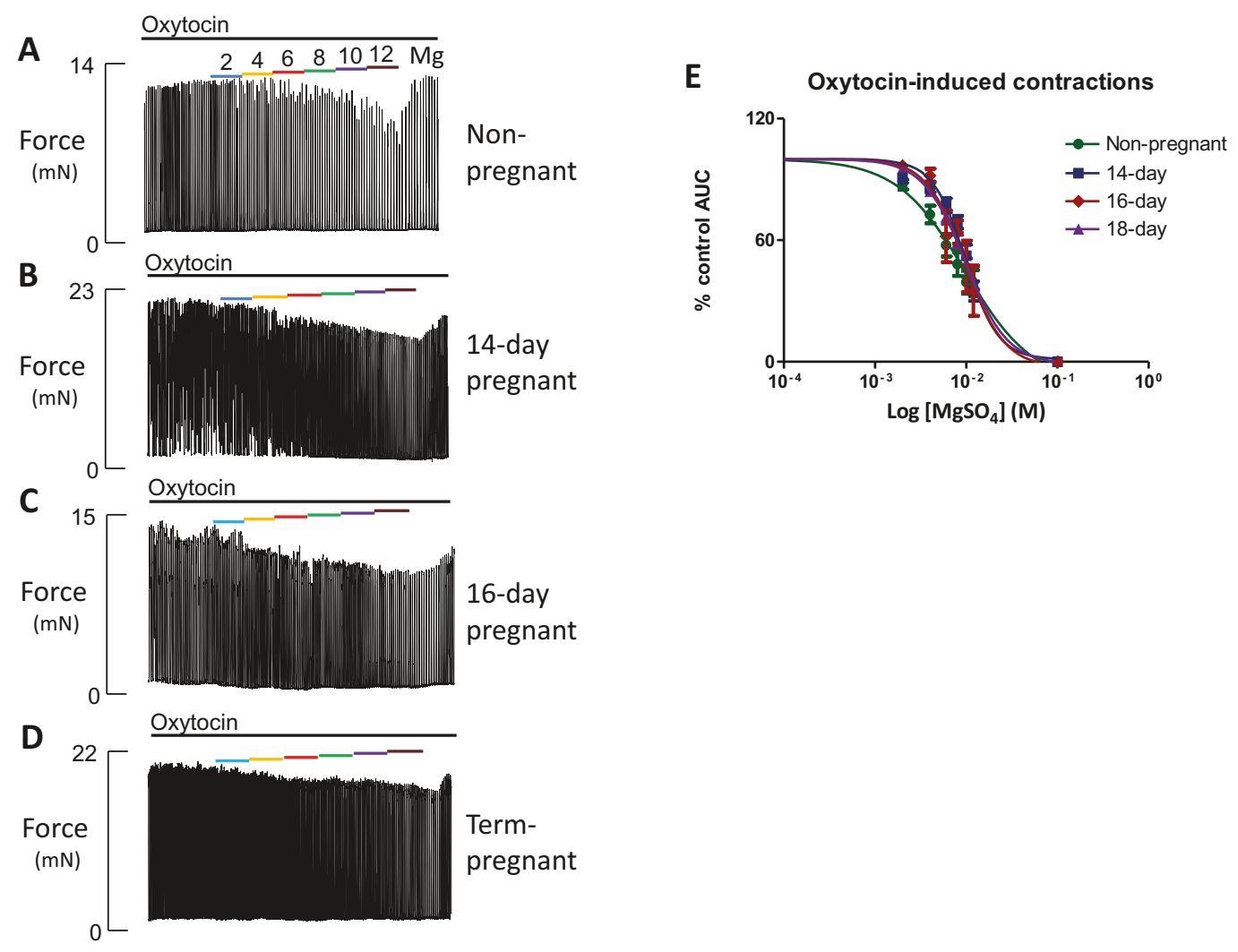

Figure 3. The effects of magnesium sulfate on oxytocin-induced contractions of mouse myometrium. Representative isometric traces showing the effect of increasing concentrations of magnesium in (A) nonpregnant myometrium, (B) I4-day pregnant, (C) I6-day pregnant, and (D) termpregnant myometrium in the presence of oxytocin ( $\mathrm{nM}$ used for nonpregnant tissue and $0.5 \mathrm{nM}$ for all pregnant tissues). The short, colored bars indicate the 15-minute period where magnesium sulfate was added. Increasing concentration of magnesium sulfate (2-I2 mM) caused gradual reduction in amplitude and frequency of contractions in all gestational states. $E$, The concentration-response curves show the effect of magnesium sulfate on AUC of contraction at different gestational states (nonpregnant: green circle, 14-day: blue square, 16-day: red diamond, term-pregnant: purple triangle). There was no significant difference between the concentration-response curves for the different gestational states, determined using ANOVA with Bonferroni post hoc test. AUC indicates area under the curve; ANOVA, analysis of variance.

magnesium as pregnancy progressed, unlike what had been found above for spontaneous conditions. Instead, in the presence of oxytocin, the potency of $\mathrm{MgSO}_{4}$ was reduced such that it was similar to its potency in nonpregnant tissues irrespective of pregnancy.

\section{Discussion}

Magnesium has been reported to suppress myometrial contractions and for this reason has been used over the past 5 decades in the treatment of preterm labor. Many clinical studies, however, including Cochrane reviews, ${ }^{3}$ conclude or suggest that $\mathrm{MgSO}_{4}$ is ineffective at delaying labor. Thus, the clinical use of $\mathrm{MgSO}_{4}$ in the treatment of preterm labor is questioned, ${ }^{30-32}$ highlighting the need for further studies. This study was conducted to better understand the effects of magnesium on uterine contractility. It was designed to examine if physiological changes, namely, gestational state and hormonal background, could influence myometrial responses to magnesium. In this way, a better understanding of the disappointing clinical findings will be obtained and perhaps suggest a more stratified approach to its use as a tocolytic, to help prevent preterm labor. Magnesium's effects as a tocolytic may synergize with its use and action to treat eclampsia. Our data provide fresh insights, as they show that preterm myometrium is much less sensitive to the relaxant effects of magnesium than term myometrium, which could explain its lack of clinical efficacy. If oxytocin was present, its efficacy was further decreased at all gestational stages. Thus, taken together, we conclude that magnesium's actions are influenced by both gestational state and hormones, such that, at least in mice, it is least effective in early gestation with oxytocin present and most effective at term in the absence of oxytocin.

\section{In Vitro Mouse Myometrium}

We conducted our study on mouse myometrium so that we could obtain myometrial preparations at several stages of gestation as well as nonpregnant tissue. Myometrium from pregnant mouse has previously been reported to produce rhythmic spontaneous contractions in vitro for many hours. ${ }^{21}$ Consistent with this, we found all the uterine strips generated spontaneous contractions which were stable within a period of 45 to 60 minutes, 

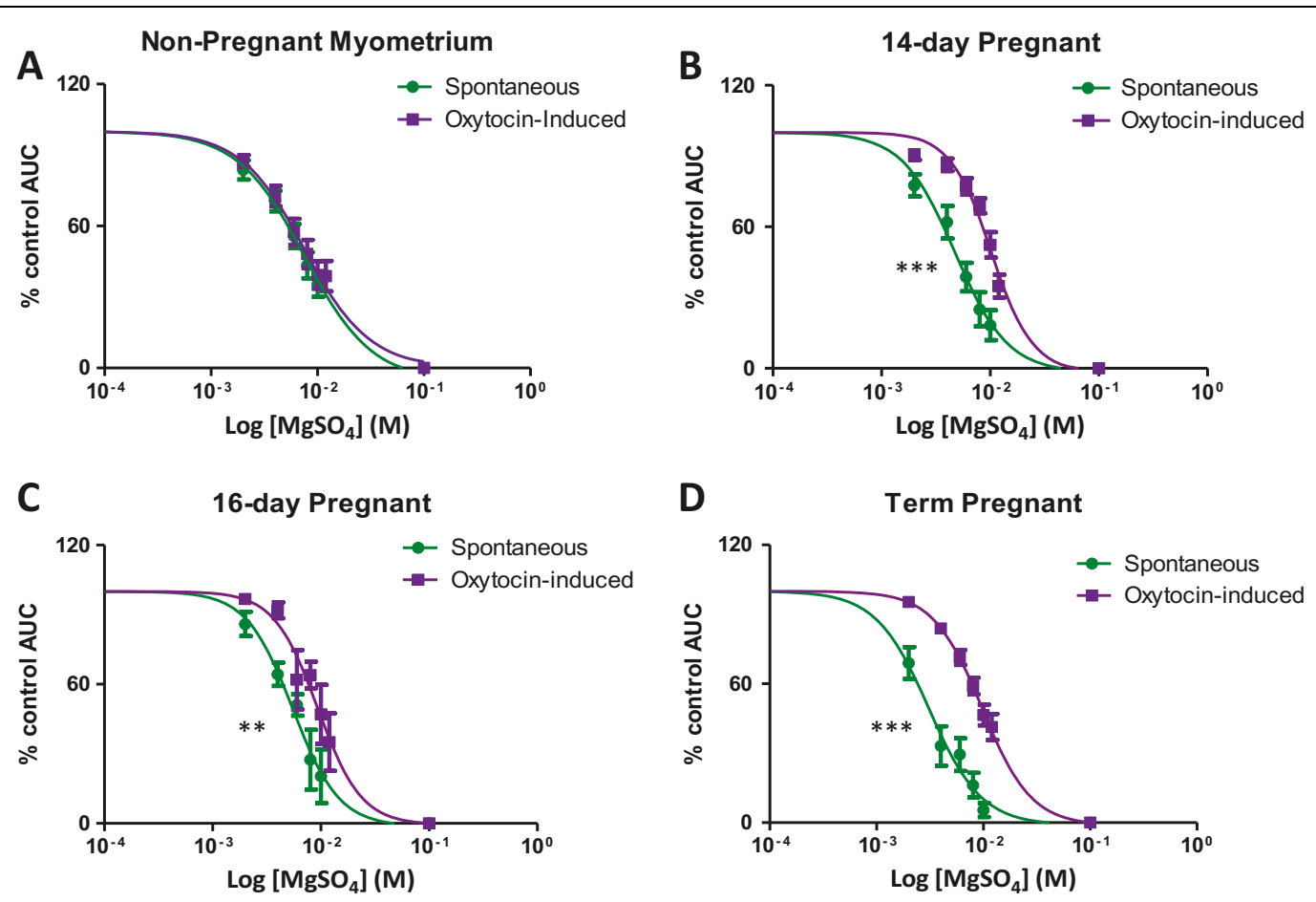

Figure 4. The effect of magnesium sulfate between spontaneous and oxytocin-induced contractions at different gestational states. The concentration-response curves show the effect of magnesium sulfate on force integral (AUC) of contraction in spontaneous (green circles) and oxytocin-induced contractions (purple squares). There was no significant difference $(P=.062)$ between the concentration-response curves of nonpregnant myometrium (A). For 14-day (B), 16-day (C), and term-pregnant myometrium (D), the concentration-response curves were significantly shifted to the right in the presence of oxytocin, indicating a significantly greater concentration of magnesium is required to reduce contractions in the presence of oxytocin compared to spontaneous contractions $(P<.000 \mathrm{I}, P<.0 \mathrm{I}$, and $P<.000 \mathrm{I}$ respectively). Significant difference in activity was determined using the extra sum of squares $F$ test. AUC indicates area under the curve; ANOVA, analysis of variance.

and remained regular without significant reduction in amplitude or frequency for many hours. This therefore allowed the effect of incremental concentrations of magnesium to be examined and concentration-response curves to be fitted. There has been just one previous report of magnesium's actions on mouse myometrium in an LPS model of preterm birth. ${ }^{27}$ These authors only studied mid-gestation (14-day) uterus and reported inhibition of spontaneous contractions with magnesium, an effect which was decreased by LPS. Our findings of an inhibitory effect on term- and nonpregnant myometrium are consistent with findings in other species, ${ }^{10,12,14,15,33}$ including humans. Future studies should attempt to obtain human biopsies at different stages of gestation to confirm these findings, although obtaining preterm biopsies is challenging. In addition, to reflect the somewhat heightened state of contraction that may be associated with preterm labor compared to the nonlaboring strips used here, a preterm labor mouse model, such as that induced by LPS or other agents, could be used to investigate the in vivo therapeutic effect of $\mathrm{MgSO}_{4}$.

\section{Magnesium's Mechanism of Action in Myometrium}

The effect of $\mathrm{MgSO}_{4}$ on contractions at different gestational stages was investigated and our data show that regardless of gestational age or pregnancy status, it can reduce myometrial contractions. This inhibitory effect was reversible and the prompt recovery after washout suggests no ill effects of magnesium on myometrium, even at high concentrations. The concentrations of $\mathrm{MgSO}_{4}$ used by us in vitro were empirically determined, and in the case of oxytocin-evoked contractions, going in to pharmacological rather than physiological concentrations, to enable maximal effects to be obtained.

It is unlikely that intracellular magnesium will have risen during the course of the experimental protocol, due to the activity of $\mathrm{Na}^{+}-\mathrm{Mg}^{2+}$ exchangers and intracellular buffers, ${ }^{34}$ as well as magnesium's slow penetrability through cell membranes. ${ }^{35}$ That the effects of magnesium on the myometrium are relatively rapid and reversible suggests that its main mechanism of action is likely to be extracellular. The rapid reversal of magnesium's effect is clinically useful, for example, if delivery is by cesarean, as it reduces the risk of postpartum hemorrhage. ${ }^{36}$ Magnesium use in preeclampsia has been associated with increased postpartum hemorrhage in some studies, ${ }^{37}$ but in another study, its use was not associated with additional blood loss. ${ }^{38}$

The major mechanism of magnesium's action to relax uterine smooth muscle is, as with other excitable tissues, due to its cationic competition with calcium. ${ }^{15}$ In myometrium, 
contractions, whether spontaneous or agonist induced, are critically dependent upon calcium entry through L-type calcium channels. ${ }^{39,40}$ Thus, when increased magnesium competes with calcium, entry of calcium falls and hence contractions reduce and can even be abolished, as we and others have shown. ${ }^{13}$ The fall in intracellular calcium will also lead to a fall in the calcium content of the SR. ${ }^{41}$ This reduced SR calcium available when agonists such as oxytocin produce $\mathrm{IP}_{3}$ will reduce their ability to increase myometrial contractility. ${ }^{15}$ In this way, magnesium will be expected to reduce the force of spontaneous and oxytocin-induced contractions. Fomin et al showed that $\mathrm{MgSO}_{4}$ reduced spontaneous, oxytocin- and $\mathrm{KCl}$-induced myometrial contractility, and all were associated with a decrease in intracellular calcium. ${ }^{34}$ In addition, they found no shift in the force-Ca relationship in the myometrium. Together, this provides strong evidence that magnesium's effects are predominantly extracellular and on calcium entry.

At all gestations and in nonpregnant tissue, our data show a significant reduction in force and frequency of contractions with addition of $\mathrm{MgSO}_{4}$. A reduction in force is most likely because of magnesium's antagonistic effect with calcium at L-type calcium channels, as discussed above. Frequency of contractions is mainly dependent on excitability and membrane potential; hence, a reduction in frequency suggests the pacemaker activity may also be affected by $\mathrm{MgSO}_{4}{ }^{11}$ For example, should differences in the resting membrane potential of some pacemaker cells exist, it may make them more susceptible to the effects of magnesium leading to fewer action potentials being triggered. ${ }^{42}$ Our figures throughout show that a decrease in the frequency of contractions usually preceded a fall in force. This finding is consistent with observations on human myometrium. ${ }^{12,43}$ Additionally, although not yet tested in uterus, magnesium may affect intercellular coupling such as via gap junctions, ${ }^{44,45}$ hence reducing the likelihood of frequent, synchronous contractions being produced.

\section{Gestational Effects}

In spontaneous contractions, the effect of $\mathrm{MgSO}_{4}$ was most potent at term, and least potent in nonpregnant tissues. The latter group were not staged for estrous and should therefore be treated as a mean of any cyclical, estrous changes. ${ }^{46,47} \mathrm{We}$ found that even on day 16 of gestation, magnesium's effect on the myometrium was significantly less than at term, suggesting that the changes in sensitivity are ongoing throughout pregnancy. Given that the underlying mechanism of magnesium's effects is via decreasing excitability and calcium entry, then our findings point to a difference in the calcium channels with gestation. There have been surprisingly few studies of L-type calcium expression with gestation in the myometrium. The work that has been done suggests an increase in expression and changes of subunits from mid-gestation onward. Tezuka et $\mathrm{al}^{16}$ found a marked increase in $\alpha-1$ expression in pregnancy, especially in the last half of gestation until term, followed by a decrease during labor. Similarly, Mershon et $\mathrm{al}^{17}$ studied the expression of $\alpha-1$ subunit and showed a gradual increase in the messenger RNA toward term followed by a decrease during parturition. They also showed an increase in the number of dihydropyridine binding sites (markers for L-type channels) in the last half of gestation. Thus, a simple effect on calcium entry is difficult to propose to explain gestational differences, unless the switch to increased $\alpha-1$ subunits confers an increased susceptibility to magnesium blockade. Rather, our data suggest that at term the effect of magnesium is enough to reduce excitability and make action potential firing less likely, as occurs with its use in neuronal tissues to protect the brain.

\section{Oxytocin and Magnesium}

To determine whether $\mathrm{MgSO}_{4}$ can affect contractile parameters in the presence of an agonist, its effect on oxytocin-evoked contractions was determined. Oxytocin was used due to its particular importance to labor. Oxytocin can directly and indirectly stimulate myometrial contractions. ${ }^{19}$ Our data show that a greater concentration of magnesium is needed to inhibit oxytocin-stimulated contractions compared to spontaneous contractions in pregnant tissues. This is in agreement with data from other studies, including human myometrium. ${ }^{14,33}$ However, oxytocin did not significantly change the $\mathrm{IC}_{50}$ for magnesium in nonpregnant tissues, from that found for spontaneous contractions. We found this to be the case even when oxytocin was used at $1 \mathrm{nM}$, that is, double the oxytocin concentration used in pregnant tissues. There was no difference in the potency of $\mathrm{MgSO}_{4}$ on oxytocin-stimulated contractions between the different gestational groups. The greatest shift in magnesium's potency with oxytocin was observed for term-pregnant myometrium; this shifted the $\mathrm{IC}_{50}$ from around $3 \mathrm{mM}$ in spontaneous conditions to almost $10 \mathrm{mM}$. In terms of clinical applications, the effect of oxytocin is to shift the dose from therapeutic to lethal. Therapeutic doses of magnesium are reported at $2.5 \mathrm{mM}(5 \mathrm{mEq} / \mathrm{L})$ or below, ${ }^{12}$ and for seizure management in preeclampsia, $3 \mathrm{mM}^{33}$

Although oxytocin acts via several mechanisms, an important mechanism is increasing membrane potential (resulting in opening of the L-type $\mathrm{Ca}^{2+}$ channels and increased calcium entry), releasing calcium from the SR and preventing calcium exit. ${ }^{19}$ These mechanisms will counteract magnesium's actions and may explain why a greater concentration of $\mathrm{MgSO}_{4}$ is needed to inhibit oxytocin-induced contractions close to term. The lipid environment around the oxytocin receptor influences its affinity for oxytocin, ${ }^{19,48,49}$ an effect attributed to its partitioning into lipid rafts and their effect on signal transduction. ${ }^{50,51}$ It was also reported that as well as high cholesterol, the high affinity form of the oxytocin receptor requires magnesium, working as an allosteric modulator. Thus, when magnesium is increased, it may increase the oxytocin signaling and further counter the relaxant effect of magnesium on calcium entry.

Transition to labor in humans is associated with increased oxytocin receptor expression, ${ }^{52}$ which increases the sensitivity of the uterus toward oxytocin. ${ }^{53}$ An increase in oxytocin receptor expression toward term in mouse has also been shown. ${ }^{53}$ 
Consistent with this is our finding that little, if any, contractility stimulation to $0.5 \mathrm{nM}$ oxytocin was observed in nonpregnant tissues and hence the use of $1 \mathrm{nM}$, to assess the effect of oxytocin on the potency of $\mathrm{MgSO}_{4}$ (control data, not shown). Although not accounting for the lack of gestational differences, the increased drive on contraction produced by oxytocin, and the increased number of receptors, and increased affinity may also partly explain why a greater concentration of $\mathrm{MgSO}_{4}$ is needed to inhibit contractions in its presence. In addition, other mechanisms operated by calcium-independent pathways may also be stimulated by oxytocin and be affected by elevated magnesium. However, the role of $\mathrm{Ca}$ sensitization in uterus is thought to be minor. ${ }^{54}$ This work, and studies by others, has not considered possible effects of magnesium on potassium channels.

\section{Conclusion}

This in vitro study shows that $\mathrm{MgSO}_{4}$, acting extracellularly, concentration-dependently, inhibits spontaneous and oxytocininduced myometrial contractions in both the pregnant and nonpregnant mouse, with greater efficacy observed in termpregnant tissues. However, oxytocin decreases the potency of $\mathrm{MgSO}_{4}$ in pregnant tissues, due to its stimulation of contraction and perhaps due to magnesium allosterically increasing the affinity of the oxytocin receptor, which may underlie its lack of efficacy as a relaxant, that is, tocolytic, in vivo.

\section{Authors' Note}

SA and SW conceived the study. BO, SA, and SW designed protocols; $\mathrm{BO}$ conducted the experimental work; $\mathrm{BO}$ and SA undertook the analysis; and BO, SA, and SW drafted, revised, and agreed the submitted manuscript.

\section{Acknowledgments}

We are very grateful to the Harris-WoW Centre for Preterm delivery research for funding this work and the University of Liverpool's Institute of translational Medicine for a studentship to BO.

\section{Declaration of Conflicting Interests}

The author(s) declared no potential conflicts of interest with respect to the research, authorship, and/or publication of this article.

\section{Funding}

The author(s) disclosed receipt of the following financial support for the research, authorship, and/or publication of this article: This work was supported by a program grant From WellBeing of Women.

\section{References}

1. Cypher RL. Reducing recurrent preterm births: best evidence for transitioning to predictive and preventative strategies. $J$ Perinat Neonatal Nurs. 2012;26(3):220-229.

2. Hall DG, McGaughey HS Jr, Corey EL, Thornton WN Jr. The effects of magnesium therapy on the duration of labour. $A m J$ Obstet Gynecol. 1959;78(1):27-32.
3. Crowther CA, Brown J, McKinlay CJD, Middleton P. Magnesium sulphate for preventing preterm birth in threatened preterm labour. Cochrane Database Syst Rev. 2014;(8

4. Crowther CA, Hiller JE, Doyle LW. Magnesium sulphate for preventing preterm birth in threatened preterm labour. Cochrane Database Syst Rev. 2002;(4):CD001060

5. Lucas MJ, Leveno KJ, Cunningham FG. A comparison of magnesium sulfate with phenytoin for the prevention of eclampsia. New Engl J Med. 1995;333(4):201-205.

6. Duley L, Gulmezoglu AM, Henderson-Smart DJ, Chou D. Magnesium sulphate and other anticonvulsants for women with preeclampsia. Cochrane Database Syst Rev. 2010;(11):CD000025.

7. Doyle LW, Crowther CA, Middleton P, Marret S, Rouse D. Magnesium sulphate for women at risk of preterm birth for neuroprotection of the fetus. Cochrane Database Syst Rev. 2009;(1): CD004661.

8. Gourgoulianis KI, Chatziparasidis G, Chatziefthimiou A, Molyvdas PA. Magnesium as a relaxing factor of airway smooth muscles. J Aerosol Med. 2001;14(3):301-307.

9. D'Angelo EK, Singer HA, Rembold CM. Magnesium relaxes arterial smooth muscle by decreasing intracellular $\mathrm{Ca}^{2+}$ without changing intracellular $\mathrm{Mg}^{2+}$. J Clin Invest. 1992;89(6): 1988-1994.

10. Kantas E, Cetin A, Kaya T, Cetin M. Effect of magnesium sulfate, isradipine, and ritodrine on contractions of myometrium: pregnant human and rat. Acta Obstet Gynecol Scand. 2002;81(9):825-830.

11. Kawarabayashi T, Kishikawa T, Sugimori H. Effects of external calcium, magnesium, and temperature on spontaneous contractions of pregnant human myometrium. Biol Reprod. 1989;40(5): 942-948.

12. Tica VI, Tica AA, Carlig V, Banica OS. Magnesium ion inhibits spontaneous and induced contractions of isolated uterine muscle. Gynecol Endocrinol. 2007;23(7):368-372.

13. Popper LD, Batra SC, Akerlund M. The effect of magnesium on calcium uptake and contractility in the human myometrium. Gynecol Obstet Invest. 1989;28(2):78-81.

14. Arrowsmith S, Neilson J, Wray S. The combination tocolytic effect of magnesium sulfate and an oxytocin receptor antagonist in myometrium from singleton and twin pregnancies. Am J Obstet Gynecol. 2016;215(6):789. e781-789. e789.

15. Phillippe M. Cellular mechanisms underlying magnesium sulfate inhibition of phasic myometrial contractions. Biochem Biophys Res Commun. 1998;252(2):502-507.

16. Tezuka N, Ali M, Chwalisz K, Garfield RE. Changes in transcripts encoding calcium channel subunits of rat myometrium during pregnancy. Am J Physiol. 1995;269(4 pt 1):C1008-C1017.

17. Mershon JL, Mikala G, Schwartz A. Changes in the expression of the L-type voltage-dependent calcium channel during pregnancy and parturition in the Rat1. Biol Reprod. 1994;51(5):993-999.

18. Collins PL, Moore JJ, Lundgren DW, Choobineh E, Chang SM, Chang AS. Gestational changes in uterine L-type calcium channel function and expression in guinea pig. Biol Reprod. 2000;63(5): 1262-1270.

19. Arrowsmith S, Wray S. Oxytocin: its mechanism of action and receptor signalling in the myometrium. J Neuroendocrinol. 2014; 26(6):356-369. 
20. Luckas MJ, Taggart MJ, Wray S. Intracellular calcium stores and agonist-induced contractions in isolated human myometrium. Am J Obstet Gynecol. 1999;181(2):468-476.

21. Matthew A, Kupittayanant S, Burdyga T, Wray S. Characterization of contractile activity and intracellular $\mathrm{Ca}^{2+}$ signalling in mouse myometrium. J Soc Gynecol Investig. 2004;11(4):207-212.

22. Blanks AM, Shmygol A, Thornton S. Regulation of oxytocin receptors and oxytocin receptor signaling. Semin Reprod Med. 2007;25(1):52-59.

23. Byrns MC. Regulation of progesterone signaling during pregnancy: implications for the use of progestins for the prevention of preterm birth. J Steroid Biochem Mol Biol. 2014;139: 173-181.

24. Shynlova O, Tsui P, Jaffer S, Lye SJ. Integration of endocrine and mechanical signals in the regulation of myometrial functions during pregnancy and labour. Eur J Obstet Gynecol Reprod Biol. 2009;144(suppl 1):S2-S10.

25. Breuiller-Fouche M, Charpigny G, Germain G. Functional genomics of the pregnant uterus: from expectations to reality, a compilation of studies in the myometrium. BMC Pregnancy Childbirth. 2007;7(suppl 1):S4.

26. Garfield RE, Saade G, Buhimschi C, et al. Control and assessment of the uterus and cervix during pregnancy and labour. Hum Reprod Update. 1998;4(5):673-695.

27. Sugawara N, Okawa T, Takahashi H, et al. Influence of lipopolysaccharide on the uterine contraction inhibitory effects of tocolytic agents in pregnant mice. Am J Perinatol. 2007;24(9): 557-562.

28. Jones K, Shmygol A, Kupittayanant S, Wray S. Electrophysiological characterization and functional importance of calciumactivated chloride channel in rat uterine myocytes. Pflugers Arch. 2004;448(1):36-43.

29. Babiychuk EB, Smith RD, Burdyga T, Babiychuk VS, Wray S, Draeger A. Membrane cholesterol regulates smooth muscle phasic contraction. J Membr Biol. 2004;198(2):95-101.

30. Grimes DA, Nanda K. Magnesium sulfate tocolysis: time to quit. Obstet Gynecol. 2006;108(4):986-989.

31. Hacivelioglu S, Cirpan T, Cosan Terek M, Kanit L, Kazandi M, Oztekin K. In vitro effects of ritodrine, magnesium sulfate and their combination on spontaneous contractions of myometrial strips of pregnant rat uteri. Clin Exp Obstet Gynecol. 2007; 34(4):223-227.

32. Keirse MJ. The history of tocolysis. BJOG. 2003;110(suppl 20): 94-97.

33. Onwochei DN, Carvalho JCA, Luca A, Balki M, Kingdom J. Effect of magnesium sulfate on oxytocin-induced contractility in human myometrium: an in vitro study. Can J Anesth. 2017; 64(7):744-753.

34. Fomin VP, Gibbs SG, Vanam R, Morimiya A, Hurd WW. Effect of magnesium sulfate on contractile force and intracellular calcium concentration in pregnant human myometrium. Am J Obstet Gynecol. 2006;194(5):1384-1390.

35. Martin RW, Gaddy DK, Martin JN Jr, Lucas JA, Wiser WL, Morrison JC. Tocolysis with oral magnesium. Am J Obstet Gynecol. 1987;156(2):433-434.
36. Lau LC, Adaikan PG, Arulkumaran S, Ng SC. Oxytocics reverse the tocolytic effect of glyceryl trinitrate on the human uterus. BJOG. 2001;108(2):164-168.

37. Szal SE, Croughan-Minihane MS, Kilpatrick SJ. Effect of magnesium prophylaxis and preeclampsia on the duration of labor. $\mathrm{Am}$ J Obstet Gynecol. 1999;180(6 Pt 1):1475-1479.

38. Graham NM, Gimovsky AC, Roman A, Berghella V. Blood loss at cesarean delivery in women on magnesium sulfate for preeclampsia. J Matern Fetal Neonatal Med. 2016;29(11):1817-1821.

39. Wray S, Kupittayanant S, Shmygol A, Smith RD, Burdyga T. The physiological basis of uterine contractility: a short review. Exp Physiol. 2001;86(2):239-246.

40. Wray S, Jones K, Kupittayanant S, et al. Calcium signaling and uterine contractility. J Soc Gynecol Investig. 2003;10(5):252-264.

41. Shmigol AV, Eisner DA, Wray S. Simultaneous measurements of changes in sarcoplasmic reticulum and cytosolic $[\mathrm{Ca}(2+)]$ in rat uterine smooth muscle cells. J Physiol. 2001;531(Pt 3):707-713.

42. Wray S, Burdyga T, Noble D, Noble K, Borysova L, Arrowsmith $\mathrm{S}$. Progress in understanding electro-mechanical signalling in the myometrium. Acta Physiol (Oxf). 2015;213(2):417-431.

43. Tang YY, Du Y, Ni J, Ma YS, Lin XM, Zhou J. Relaxant effects of metoclopramide and magnesium sulfate on isolated pregnant myometrium: an in vitro study. Int J Obstet Anesth. 2014;23(2): 131-137.

44. Matsuda H, Kurata Y, Oka C, Matsuoka S, Noma A. Magnesium gating of cardiac gap junction channels. Prog Biophys Mol Biol. 2010;103(1):102-110.

45. Rimkute L, Kraujalis T, Snipas M, et al. Modulation of connexin36 gap junction channels by intracellular $\mathrm{pH}$ and magnesium ions. Front Physiol. 2018;9:362.

46. Dodds KN, Staikopoulos V, Beckett EA. Uterine contractility in the nonpregnant mouse: changes during the estrous cycle and effects of chloride channel blockade. Biol Reprod. 2015;92(6):141.

47. Wray S, Noble K. Sex hormones and excitation-contraction coupling in the uterus: the effects of oestrous and hormones. $\mathrm{J} \mathrm{Neu}$ roendocrinol. 2008;20(4):451-461.

48. Gimpl G, Fahrenholz F. The oxytocin receptor system: structure, function, and regulation. Physiol Rev. 2001;81(2):629-683.

49. Noble K, Zhang J, Wray S. Lipid rafts, the sarcoplasmic reticulum and uterine calcium signalling: an integrated approach. J Physiol. 2006;570(Pt 1):29-35.

50. Smith RD, Babiychuk EB, Noble K, Draeger A, Wray S. Increased cholesterol decreases uterine activity: functional effects of cholesterol alteration in pregnant rat myometrium. Am J Physiol Cell Physiol. 2005;288(5): C982-C988.

51. Draeger A, Wray S, Babiychuk EB. Domain architecture of the smooth-muscle plasma membrane: regulation by annexins. Biochem J. 2005;387(Pt 2):309-314.

52. Kimura T, Tanizawa O, Mori K, Brownstein MJ, Okayama H. Structure and expression of a human oxytocin receptor. Nature. 1992;356(6369):526-529.

53. Kubota Y, Kimura T, Hashimoto K, et al. Structure and expression of the mouse oxytocin receptor gene. Mol Cell Endocrinol. 1996;124(1):25-32.

54. Wray S. Insights into the uterus. Exp Physiol. 2007;92(4): 621-631. 